\title{
Power Voltage Characteristics of Fabricated DSSC Incorporating Multiple Organic Dyes as Photosensitizer
}

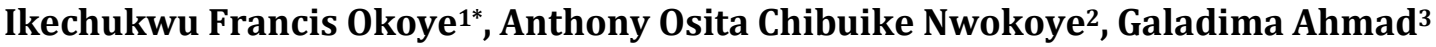 \\ ${ }^{1}$ Department of Physics, Federal University Gusau, Gusau, Nigeria \\ ${ }^{2}$ Department of Physics and Industrial Physics, Nnamdi Azikiwe University, Awka, Nigeria \\ ${ }^{3}$ Centre for Research, Federal University Gusau, Gusau, Nigeria \\ Email: ^fitechfrank@gmail.com, aoc.nwokoye@unizik.edu.ng, ahmadgldm@yahoo.com
}

How to cite this paper: Okoye, I.F., Nwokoye, A.O.C. and Ahmad, G. (2021) Power Voltage Characteristics of Fabricated DSSC Incorporating Multiple Organic Dyes as Photosensitizer. Energy and Power Engineering, 13, 221-235.

https://doi.org/10.4236/epe.2021.136015

Received: September 15, 2020

Accepted: June 8, 2021

Published: June 11, 2021

Copyright $\odot 2021$ by author(s) and Scientific Research Publishing Inc. This work is licensed under the Creative Commons Attribution International License (CC BY 4.0).

http://creativecommons.org/licenses/by/4.0/

\begin{abstract}
Two sets of Organic dyes were developed using kassod and senna plant leaves. The first sets of dyes are the organic dye from the leaves of two plants while the second set is the dye produce after combining together the dyes from the kassod and senna plants leaves. The two sets of dyes were used to sensitize the grown films. The films were characterized and the current voltage values of the grown films were obtained. The solar simulation result of the grown film for Kassod dyed $\mathrm{TiO}_{2}$ film was recorded for single dyes and for the combination of the two dyes. The result also covers absorbance of the spectra lines, absorbance coefficient values of the dyed $\mathrm{TiO}_{2}$, as well as transmittance and energy band gap values of the developed films. The precursors of tin (IV) chloride $\left(\mathrm{SnCl}_{4}\right)(60 \%)$ and hydrofluoric acid $(40 \%)$ was deposited on the cleaned soda-lime glass using the chemical vapour deposition method and nitrogen gas was supplied as a carrier gas through the bubbler to form the FTO layer. Titanium dioxide paste $\left(\mathrm{TiO}_{2}\right)$ was deposited using a screen printing method to form $\mathrm{M}-\mathrm{TiO}_{2}$.
\end{abstract}

\section{Keywords}

Current Voltage, Substrate, Efficiency, Spectra Lines, Transmittance and Energy Band Gap

\section{Introduction}

The concept of DSSC was invented in 1988 by Brian O'Regan and Michael Gratzel at UC Berkeley [1]. Dye-sensitized solar cell operation is based on a semiconductor formed between a photon-sensitized anode and an electrolyte, a pho- 
toelectrochemical system [2] [3]. One of the important qualities of the plant is that it has the ability to produce pigment and chlorophyll we use for production of organic dye [2] [3]. The green leaves and flower of a plant are one of the natural storage units of energy [2]. The energy transformation that takes place in DSSC formed using organic dye produced from plants try to replicate the natural processes of photosynthesis that take place in the chlorophyll leaf of a plant [1]-[7]. In this work, the energy locked in the leaf of plants was extracted using the water extraction method and harnessed as the organic dye used as photosensitizers. The organic dye is used as a photo-sensitizer to sensitize the substrate doped with $\mathrm{TiO}_{2}$ for a period of twelve hours before annealing it at a certain temperature to allow the deposited dyed $\mathrm{TiO}_{2}$ to settle inside the substrate [8]-[15]. The presence of dye on the substrate will form a dye layer on top of the substrate and allow the substrate to absorb photon energy and conduct electricity even at room temperature [1]. DSSC is the only device that absorbs the photon and converts them to electric charge without the need for intermolecular transport of electronic excitation [3] [16] [17] [18]. In conventional solar cells, both light absorption and charge carrier transport were performed simultaneously, whereas in DSSC the two operations are performed separately. Solar simulation of the doped substrate enables us to identify the rate of current voltage characteristics of a particular cell or DSSC and other parameters required for developing a DSSC [1]. The operating cycle can be summarized in chemical reaction [16]-[25]. The organic dye (Q) will be excited and inject electrons in the conduction band as shown in Equation (1).

Anode: $h v+Q \rightarrow Q^{*}$ Excitation

where $h v$ is the incoming photon and $\mathrm{Q}^{*}$ is the excited organic dye. The excited dye will inject electrons into the conduction band of $\mathrm{TiO}_{2}$ according to the injection process Equation (2):

$$
\mathrm{Q}^{*} \rightarrow \mathrm{Q}^{+}+\mathrm{e}_{\mathrm{cb}}^{-}\left(\mathrm{TiO}_{2}\right)
$$

The excited dye will be oxidized. The oxidized dye molecules will be reduced by an Iodide ion which in turn becomes a tri-iodide ion following regeneration given by Equation (3):

$$
\begin{gathered}
2 \mathrm{Q}^{+}+3 \mathrm{I}^{-} \rightarrow \mathrm{I}_{3}^{-}+2 \mathrm{Q} \\
\text { Cathode: } \mathrm{I}_{3}^{-}+2 \mathrm{e}^{-} \rightarrow 3 \mathrm{I}^{-} \\
\mathrm{Q}^{*}+\mathrm{e}_{\mathrm{cb}}^{-}\left(\mathrm{TiO}_{2}\right) \rightarrow \mathrm{Q}^{+}+\mathrm{e}_{\mathrm{cb}}^{-}\left(\mathrm{TiO}_{2}\right) \\
\mathrm{I}_{3}^{-}+2 \mathrm{e}_{\mathrm{cb}}^{-}\left(\mathrm{TiO}_{2}\right) \rightarrow 3 \mathrm{I}_{3}^{-}+\left(\mathrm{TiO}_{2}\right) \\
\text { Cell: } 2 \mathrm{e}^{-}(\mathrm{pt})+h v \rightarrow 2 \mathrm{e}^{-}\left(\mathrm{TiO}_{2}\right)
\end{gathered}
$$

According to [23]-[28], the electron in the conduction band of $\mathrm{TiO}_{2}$ flows through the external circuit while at the counter electrode, the reactions from Equations (3) and (4) have to be effective and compete with the recombination reactions in order to generate high current. The aim of this paper is to show the 
power voltage characterization of fabricated DSSC incorporating multiple organic dyes as photosensitizer.

\section{Experimental Procedure}

\section{1) Preparation of Fluorine Doped Tin Oxide (FTO) Film}

Flourine doped tin oxide thin film is the grown films developed as a result of precursors of tin (IV) chloride $\left(\mathrm{SnCl}_{4}\right)(60 \%)$ and hydrofluoric acid (40\%) deposited on the cleaned soda lime glass and nitrogen gas which was used as carrier gas using chemical vapour deposition method.

Nitrogen gas was supplied from a cylinder through a pressure regulator (Glook scientific) set at 0.5 bars and then through a mass flow controller (Alicat Scientific). The flow rate was set at 1 litre per minute and then through a bubbler containing $\mathrm{SnCl}_{4}$ (anhydrous).

A separate gas stream at 1 litre per minute is bubbled through the hydrofluoric acid precursor.

The two gas streams converge on the substrate maintained at $550^{\circ} \mathrm{C}$ by means of a thermocouple and temperature controller (Rex C-900).

A chemical reaction took place leading to the deposition of a transparent and conductive FTO thin film. The deposition time is varied between 1 minute and 5 minutes to generate films of a transparent and conductive quality. FTO usually generates films of different conductivities and transparency.

\section{2) Preparation of Natural Dyes}

The natural dyes are the dyes prepared using Kassord Plant (Cassia siamea) and Senna Plant (Senna occidentalis). The dyes were prepared individually using the same procedures, measurement, timing, ratio of water and methanol. Five grams ( $5 \mathrm{~g}$ ) of each leave were measured using weighing balance. Mixture of 60 $\mathrm{ml}$ water and methanol (50:50 ratios) was measured using conical cylinder and poured into an electronics grinder. The $5 \mathrm{~g}$ of leave and $60 \mathrm{ml}$ of solvent (50:50 ratios of water and methanol) was grinded for 5 minutes. The solution was filtered after grinding and the dye separated and poured into a cylinder. The filtrate was filtered again by placing the solution on centrifuge machine. The centrifuge machine was allowed to operate for 3 minutes to allow the natural dye from the leaf settle on top of the cylinder while the waste product clustered at the bottom of the cylinder. The filtered dye was transferred to a small container and covered. Mixture of $60 \mathrm{ml}$ Kassord Plant (Cassia siamea) and Senna Plant (Senna occidentalis) dyes (50:50 ratios) was measured using conical cylinder and poured together in a cylinder. The solution of combined dye was placed on centrifuge machine and allowed to centrifuge for 3 minutes to allow the natural dyes mix together.

\section{3) Sensitization of Natural Dye and Nanocrystalline $\mathrm{M}-\mathrm{TiO}_{2}$ Thin Film}

Doped substrate was soaked into the prepared natural dye. After soaking the nanocrystalline substrate inside the dye, the soaked substrate was washed using the prepared solvent (50:50 ratio of water and methanol). The substrate was 
dried using REX-C900 hot plate machine under the temperature of $80^{\circ} \mathrm{C}$ for 3 minutes. The UV spectroscopic data capturing was carried out on the three set of prepared dyes using UV spectrometer to find out the absorbance rate of each dye and that of $\mathrm{TiO}_{2}$ substrate. The generated data was used to calculate the absorptance spectra, transmittance value, energy band gap, fill factor FF, short circuit current Isc, open circuit voltage $V_{o C}$, maximum power point $M_{P P}$, sheet resistance $R_{\text {sh }}$, serial resistance $R_{\text {send }}$, efficiency of the solar cell, Tauc plot for band gap calculation and Beer-Lambarts law.

The elococab layer acts as counter electrode of monolithic dye sensitized solar cell. Elcocab paste was deposited using screen printing method. At the end of deposition, the substrate was dried and annealed at $400^{\circ} \mathrm{C}$.

After drying the films, a drop of iodolyte (AN 50 electrolyte) was added on top of the substrate. The iodolyte electrolyte will sink through the elcocab.

Simulated solar irradiation was provided by a solar simulator, model 4200 -scs semiconductor characterization system under the irradiation of AM 1.59100 $\mathrm{mW} \cdot \mathrm{cm}^{-2}$. The current voltage curves were recorded by a digital keithley multimeter model 2400 coupled to a computer.

Amosil $4 \mathrm{R}$ and Amosil $4 \mathrm{H}$ gums were mixed together and used to gum the glass together with the cell. The two gums were mixed together and screen printed on the mapped out dimension of the cell before placing the glass that were used to cover the cell.

\section{Results and Discussions}

Figure 1 and Figure 2 show the absorbance as a function of wavelength for Kassod and Senna (liquid and solid respectively).

It was noticed that as the wavelength increases the absorbance decrease in all the samples. The liquid samples recorded the highest absorbance as they absorb more cells compared to the solid samples. The liquid sample recorded absorbance above 2.0 a.u while the solid sample absorbance lies within $0.1-0.27$. From the plots, the solid sample absorbance will be suitable for the solar application while the liquid sample will be suitable for photovoltaic application.

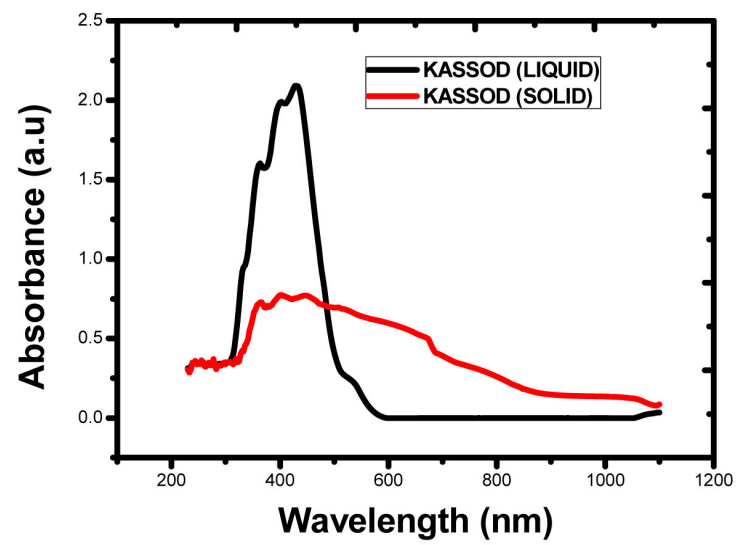

Figure 1. Plot of absorbance vs wavelength for Kassod (liquid and solid sample). 


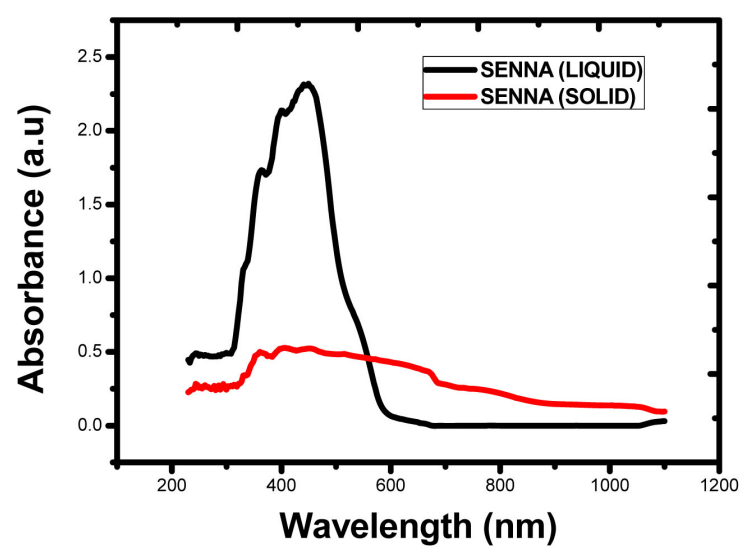

Figure 2. Plot of absorbance vs wavelength for Senna (liquid and solid sample).

Figure 3 shows the absorbance as a function for Kassod and Senna combined (liquid and solid) samples.

It was observed that as the wavelength of the incident radiation increases the absorbance increase from the ultraviolet and infrared region. The Kassod + Senna (liquid sample) absorbed more cells at both regions compared to the solid sample. This high absorbance in the UV region combined Kassod and Senna plant samples useful in p-n junction formation of solar cells with other suitable thin film materials for photovoltaic applications. However, the low absorption of Kassod and Senna solid sample Plants in the infrared makes it useful for the mass production of solar cells and for the fabrication of solar panel.

UV transmittance analyses of dyed $\mathrm{TiO}_{2}$ were carried out for the samples as before. Figures 4-6 show the plots of transmittance against wavelength for Kassod and Senna Plants synthesized on FTO.

The plots show that the transmittance increases as the wavelength of incident radiation increases for the transmittance above $56 \%$ in the infrared region and transmittance below $45 \%$ in the ultraviolet region. The plot revealed that Kassod plant has the highest transmittance of about $57 \%$. Films of low transmittance in the infrared region are used in the mass production of solar cells and for the fabrication of solar panel, while films with high transmittance in the ultraviolet region are useful in photosynthetic coatings as they exhibit selective transmittance of photosynthetic active radiation (PAR) and also used as reflector and dielectric filter.

The band gap energy and transition types were derived from mathematical processing of the data obtained from the optical absorbance as a function of wavelength with the following relationships for near edge absorption as in Equation (8):

$$
\alpha=\left(h v-Y_{g}\right)^{\frac{n}{2}},
$$

where $\alpha$ is the absorption coefficient, $v$ is the frequency, $h$ is the Planck's constant, $Y_{g}$ is the band gap energy while $\mathrm{n}$ carries the value of either 1 or 4 . The band gap energy could be obtained from a straight line plot of $\alpha^{2}$ as a function of 


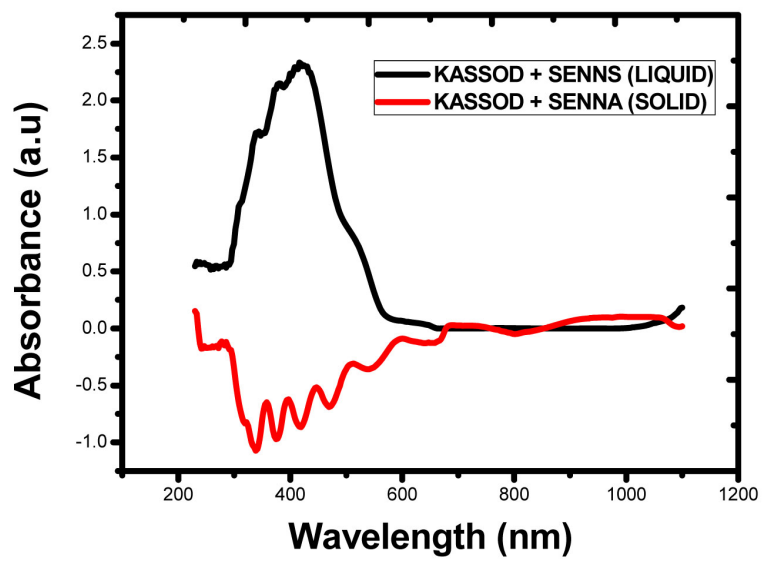

Figure 3. Plot of absorbance vs wavelength for Kassod + Senna (liquid and solid sample).

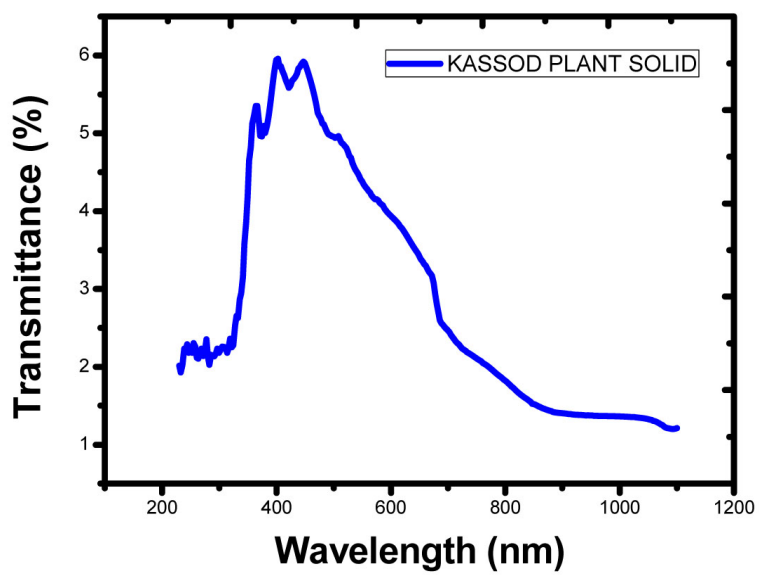

Figure 4. The plot transmittance (\%) as a function wavelength for Kassod plant.

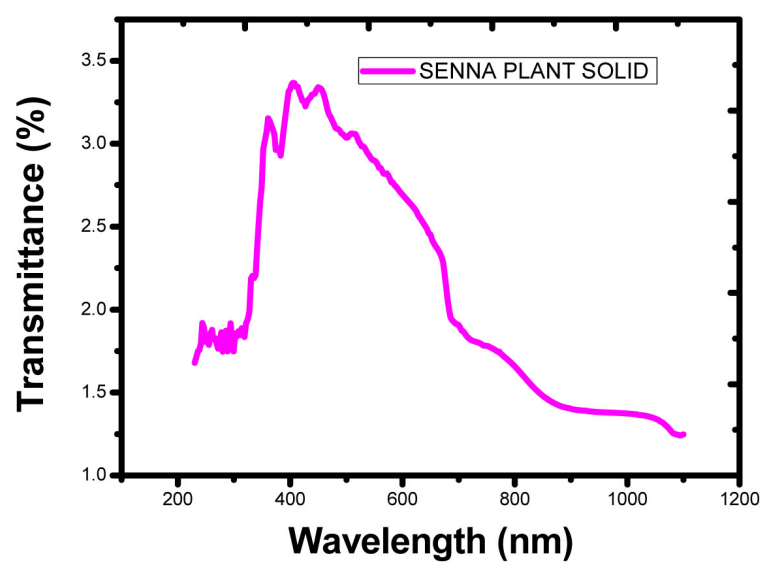

Figure 5. The plot transmittance (\%) as a function wavelength for Senna plant.

$h v$ and by extrapolation of the straight line portion of the plot on the energy axis and results to band gap energy. If a straight line graph is obtained from $n=1$, it indicates a direct transition between the states of the semiconductor, whereas the transition is indirect if a straight line graph is obtained from $n=4$ as shown in Figures 7-9. 


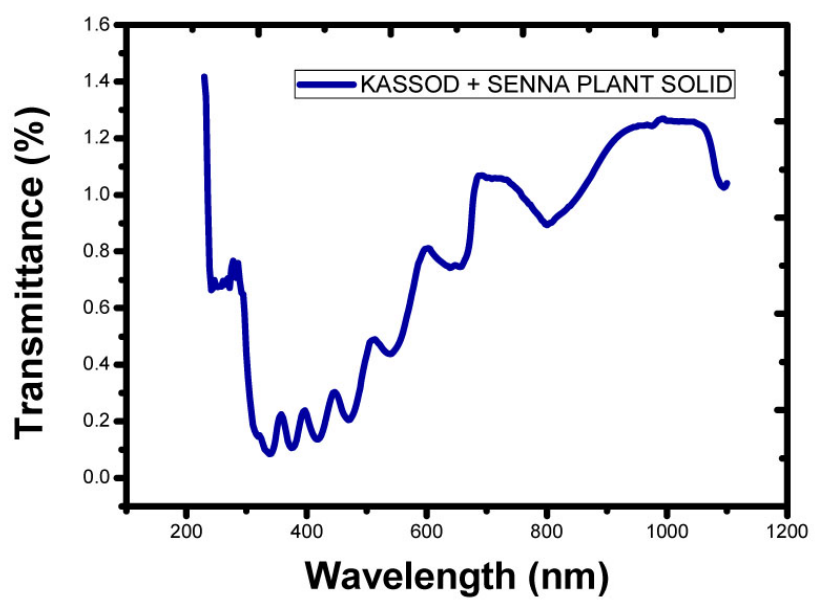

Figure 6. The plot transmittance (\%) as a function wavelength for Kassod + Senna plant solid.

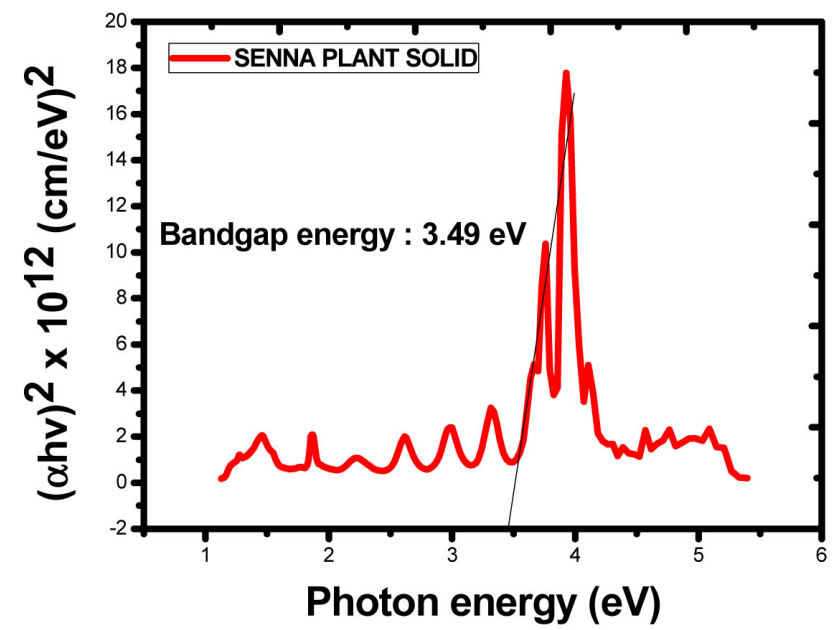

Figure 7. The plot of absorption coefficient square as a function photon energy for Senna plant.

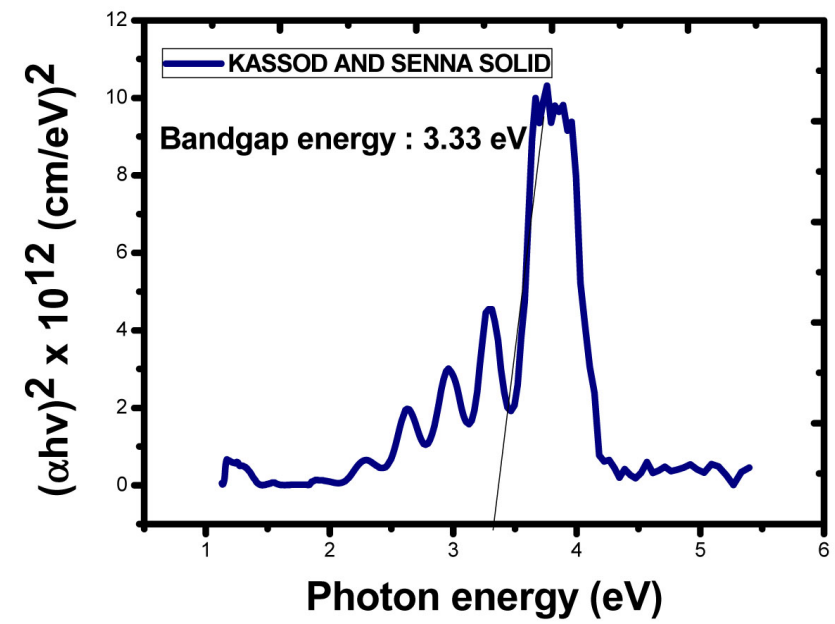

Figure 8. The plot of absorption coefficient square as a function photon energy for Kassod + Senna. 


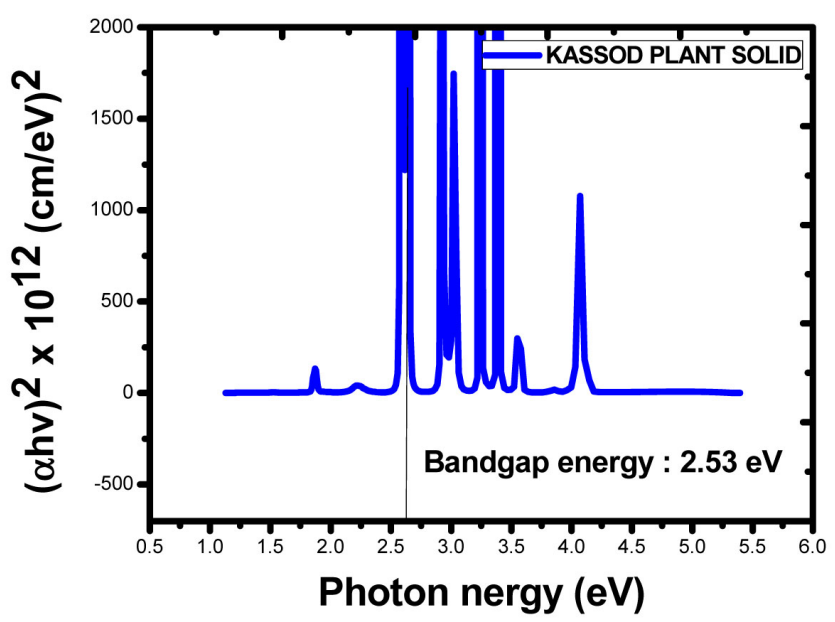

Figure 9. The plot of absorption coefficient square as a function photon energy for Kassod plant.

The band gap energy as obtained for Kassod, Senna, and Kassod + Senna Plants synthesized on FTO was in the range of $1.25-3.71 \mathrm{eV}$. From the fig, it is observed that the absorption coefficient squared increases exponentially with photon energy. The range of the band gap energy makes the material useful for fabrication of blue and green light emitting devices, photocell window layer and light emitting laser diode.

Figures 10-12 reveal the plot of absorption coefficient as a function of photon energy. Absorption coefficient determines how far light enters into a material of a particular wavelength before it is absorbed.

The absorption coefficient spectra of Kassod and Senna films showed that the films have a sharp edge at the lower energies. Thus the light energies below the band gap (3.0 eV and above) do not have sufficient energy to excite an electron into the conduction band from the valence band. Consequently, the light was not absorbed. But, as the photon energy increased sufficiently to about $3.25 \mathrm{eV}$, the absorption coefficient increases with the photon energy. Materials with higher absorption coefficients such as Senna plant, more readily absorbs photons which excite electrons into the conduction band.

The absorption coefficient as a function of photon energy shows a steady relationship at lower energy. As the energy increases up to $2.5 \mathrm{eV}$, the rate of decrease of the radiation, increases at increasing photon energy. The result provides evidence of significant dependence on $\mathrm{TiO}_{2}$.

The efficiency of the Kasod, Senna and their combined dyed $\mathrm{TIO}_{2}$ is shown.

The current density plots as a function of the voltage are shown in Figures 13-15.

The Kassod, Senna Plant, and Kassod + Senna Plants natural dye extracts revealed good absorbance. The efficiency of a solar cell and incident power converted to electricity was determined using Equation (9)

Ideally, an excellent dye should absorb very well for all wavelengths below 920 $\mathrm{nm}$. The DSSCs fabricated using these natural dyes gave overall photocurrent 


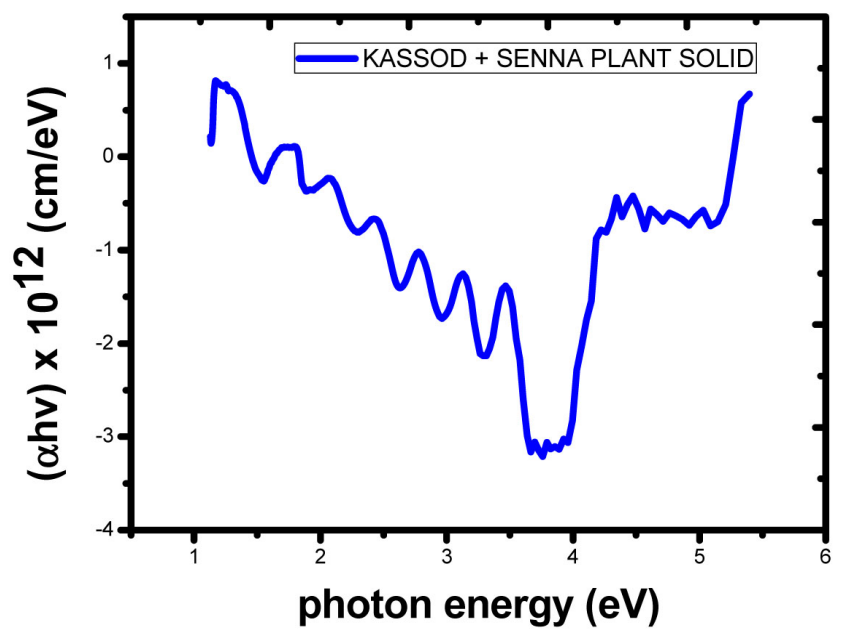

Figure 10. The plot of absorption coefficient as a function photon energy for Kassod + Senna plant solid.

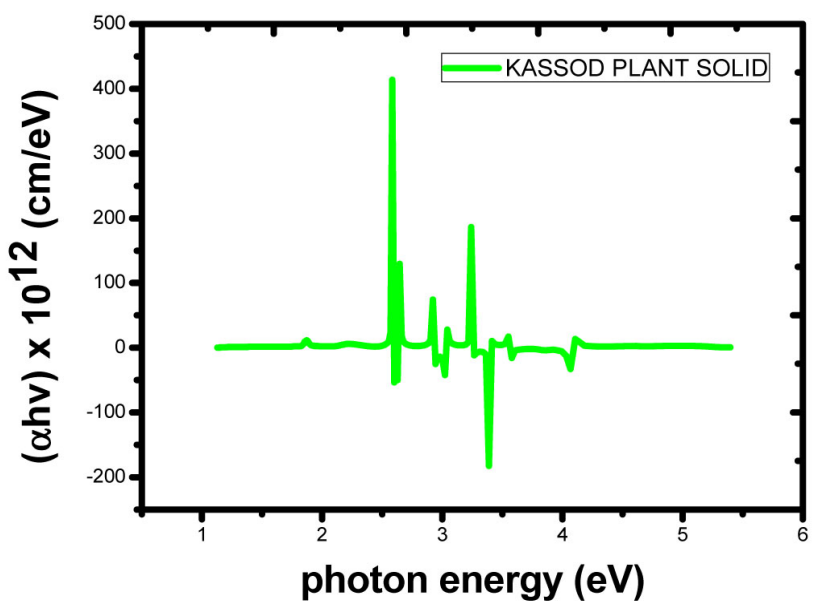

Figure 11. The plot of absorption coefficient as a function photon energy for Kassod plant solid.

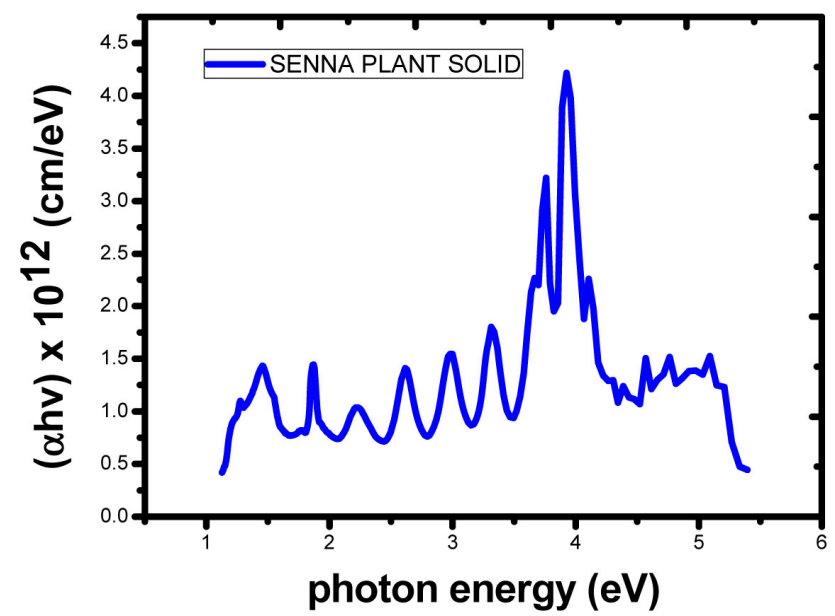

Figure 12. The plot of absorption coefficient as a function photon energy for Senna plant solid. 


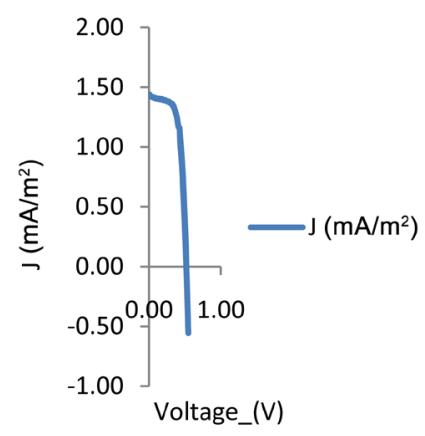

(a)

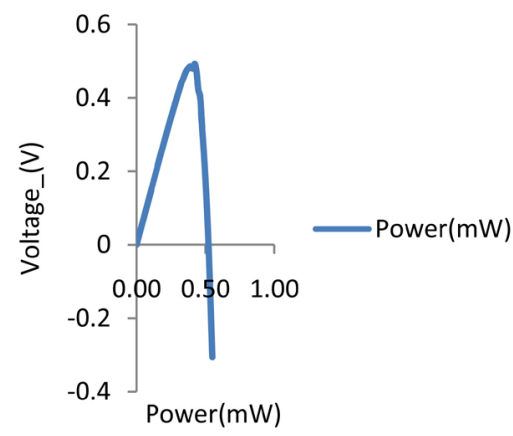

(b)

Figure 13. (a): Current/voltage for Kassod plant; (b): Voltage/power curve for Kassod plant.

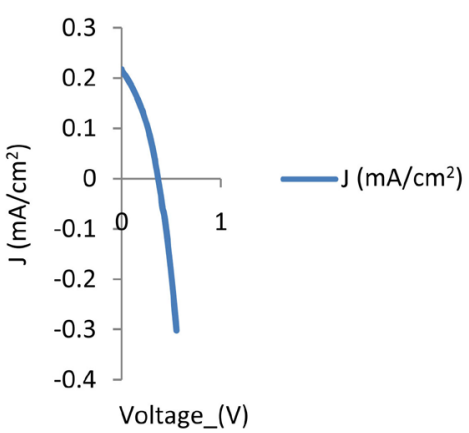

(a)

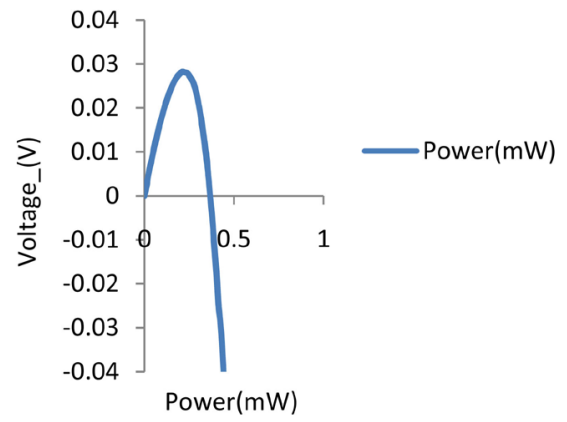

(b)

Figure 14. (a): Current/voltage for Senna plant; (b): Voltage/power curve for Senna plant.

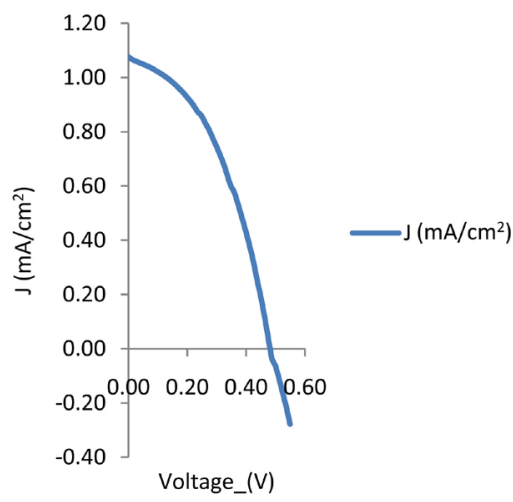

(a)

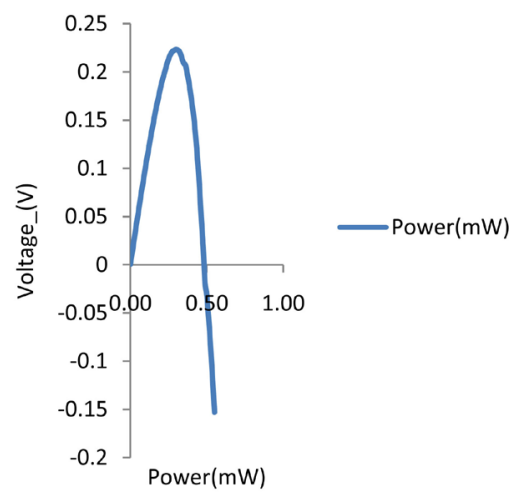

(b)

Figure 15. (a): Current/voltage for Kassod + Senna Plant; (b): Voltage/power curve for Kassod + Senna Plant.

conversion efficiencies of $\eta 0.492 \%, 0.028 \%$, and $0.0223 \%$ respectively. However, the Kassod plant outperformed the others probably due to the dye molecules' ability to anchor more firmly to the surfaces of the $\mathrm{TiO}_{2}$. Moreover, the solar cell fabricated using the Kassod plant dye exhibited high shunt 10 resistances which implies that there were fewer alternative paths for current leakage in the cell. One of the greatest challenges to $\mathrm{TiO}_{2}$ DSSCs is its ability to strongly adsorb dye molecules. 
Figures 16(a)-(d) shows the thickness and shape of the scanning electron microscope (SEM) images of the $\mathrm{TiO}_{2}$ (anatase) grown thin films deposited by screen printing on FTO glass slide while Figure 17 shows the graph of the EDX analysis of the grown film. SEM analysis revealed that the particles contained in the grown film are irregular and the surface morphology was rough. The porosity found on the surface of $\mathrm{TiO}_{2}$ is a result of the degree of thermal treatment, time given to the thin film during annealing processes and cooling rate given to the nanoparticles deposited in the film [2] [3] [4]. The porosity allows electrons

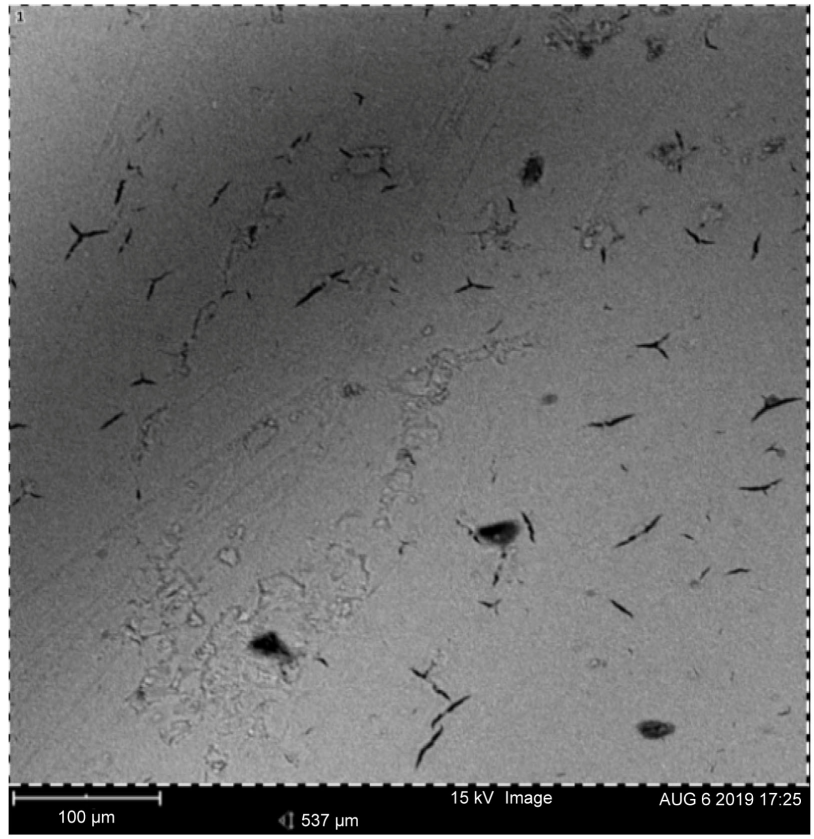

(a)

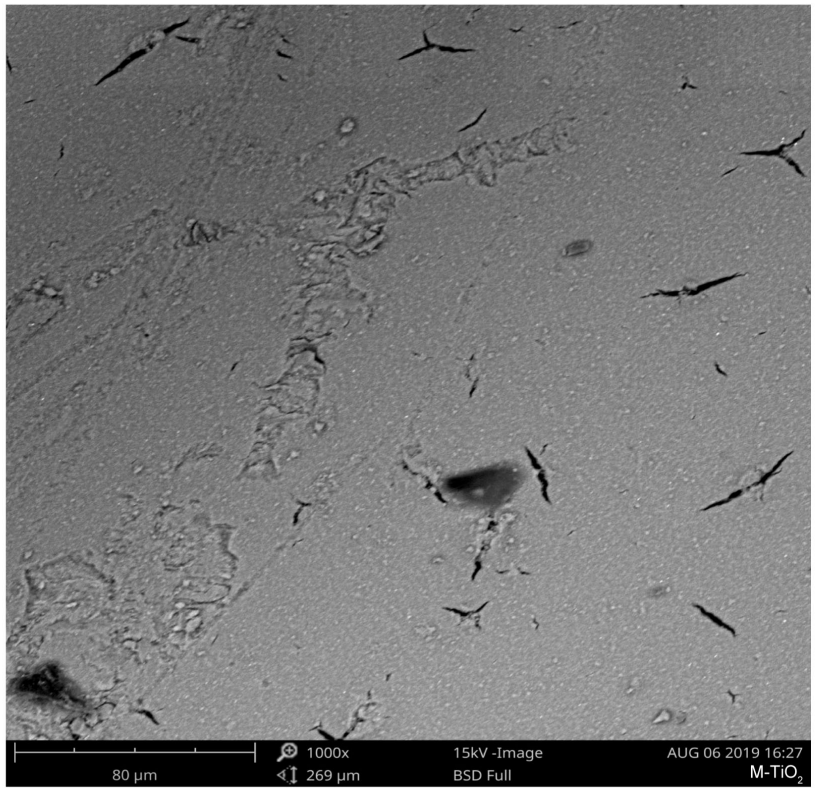

(c)

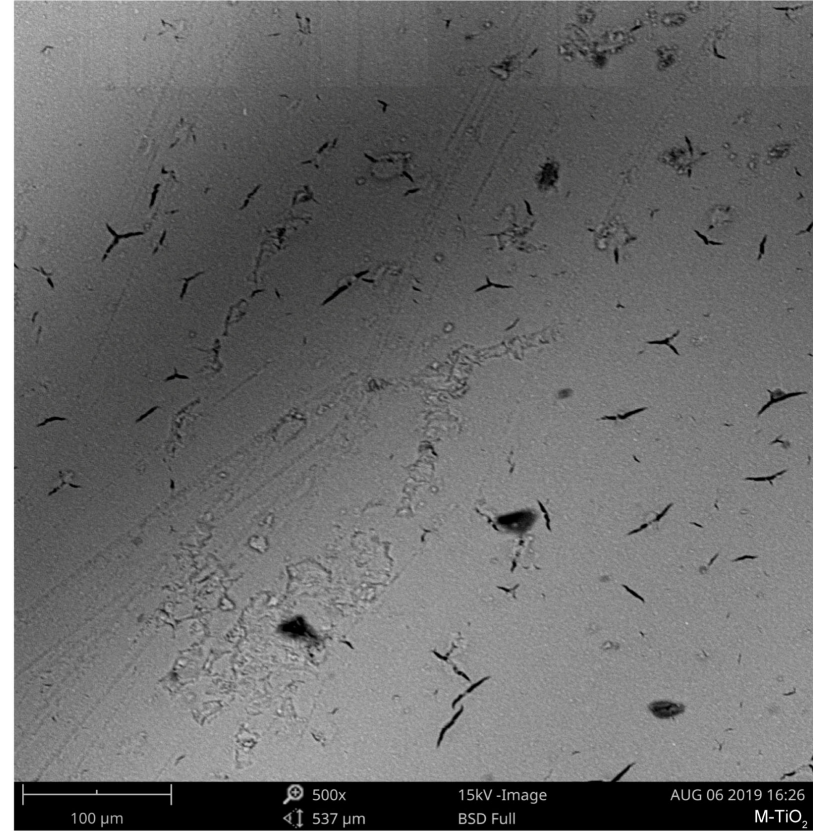

(b)

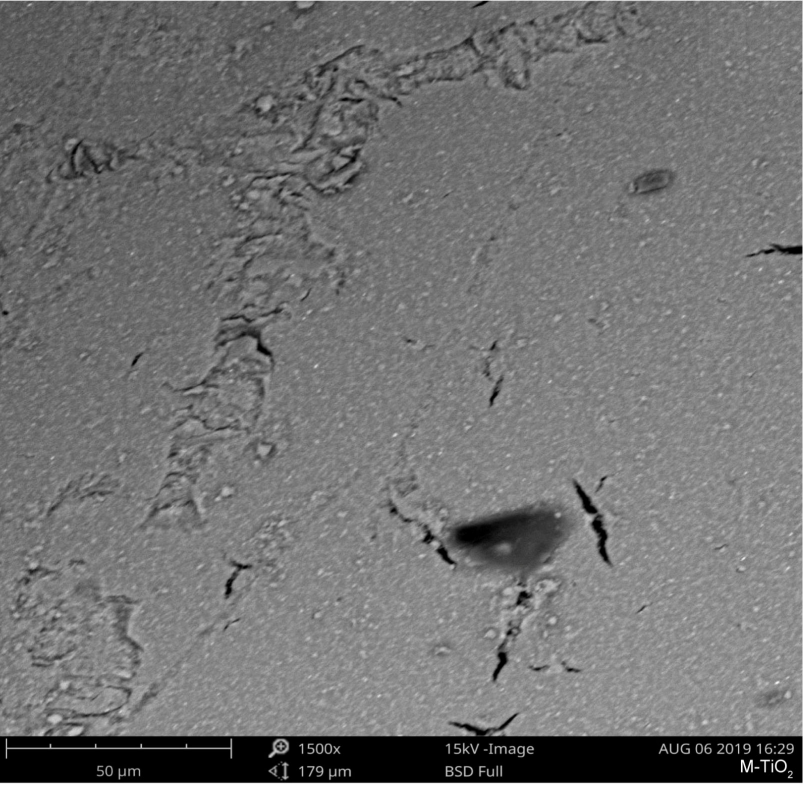

(d)

Figure 16. (a)-(d): Show the SEM analysis. 


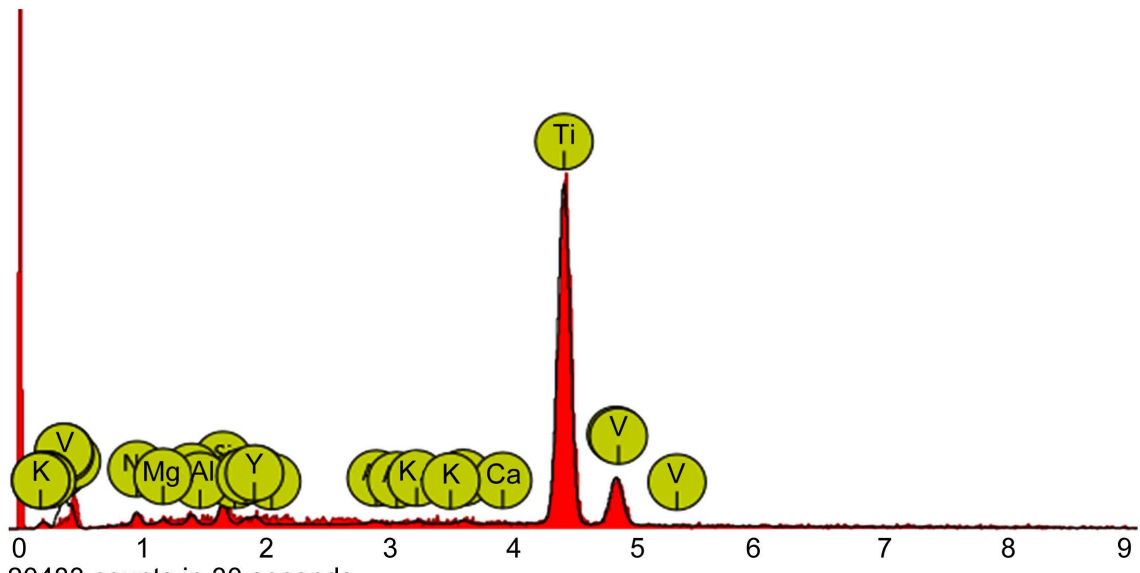

20483 counts in 30 seconds

Figure 17. EDX analysis.

to move around the surface. The generated electrons were absorbed at the conducting substrate (FTO layer). The $\mathrm{TiO}_{2}$ nanoparticles produced have thickness of $14 \mu \mathrm{m}$. The morphology shows that the $\mathrm{TiO}_{2}$ paste have agglomeration particle size with spherical shape doted on the film as shown in Figure 17. The thermal treatment given to the $\mathrm{TiO}_{2}$ thin film allows the internal gas, voids that clusters on top of the film layer to be eliminated as well as the impurity found on the substrate. Elimination of these particles leads to the creation of holes on the morphology of the films and increase in the quantity of $\mathrm{TiO}_{2}$ nanoparticles in a particular section of the film thereby enhancing the absorptive capability of natural dye molecules. The films in Figures 16(a)-(d) were deposited using screen printing method parameters of (a) $0.2 \mathrm{~g} / \mathrm{l}, 15 \mathrm{kV}, 537 \mu \mathrm{m}$ and $17 \mathrm{hrs}: 25 \mathrm{~S}$ (b) 0.2 g/l, $15 \mathrm{kV}, 100 \mu \mathrm{m}$ and $16 \mathrm{hrs:} 26 \mathrm{~S}$ (c) $0.2 \mathrm{~g} / \mathrm{l}, 15 \mathrm{kV}, 80 \mu \mathrm{m}$ and $16 \mathrm{hrs:} 27 \mathrm{~S}$ (d) $0.2 \mathrm{~g} / \mathrm{l}, 15 \mathrm{kV}, 50 \mu \mathrm{m}$ and $16 \mathrm{hrs}: 29 \mathrm{~S}$. The SEM images of $\mathrm{TiO}_{2}$ thin films shows that film at 17 hrs: $25 \mathrm{~S}$ formed some cracks in Figure 16(a) more than those deposited time in Figures 16(b)-(d); 16 hrs: 26 S, 16 hrs: 27 S and 16 hrs: 29 S respectively. Extending deposition time provides more particles to move and form thicker films. These results concur with other studies [29] which confirmed that film quality deteriorates when deposition time is extended. The SEM images show that $\mathrm{TiO}_{2}$ dye particles formed in the grown films were spherical in structures. These qualities make the film to be more compatible with various metallic and polymeric matrices in lattice structure resulting to a more usefulness in the production of solar cells and for the fabrication of solar panel [1] [2] [3] [4] [5].

\section{Conclusion}

The research on power voltage characteristics of fabricated DSSC incorporating multiple organic dyes as photosensitizer was successfully carried out. The FTO films were grown using the chemical vapour deposition method and screen printing method to deposit the precursors and $\mathrm{TiO}_{2}$ dye paste respectively. The three films characterized have absorbance, transmittance, coefficient of absorbance as well as energy band gap and solar simulation results. The SEM and 
EDX results were also provided. The current voltage values of each film were obtained using four-point probe solar simulation characterization. The solar simulation results obtained are $\left(\mathrm{I}_{\mathrm{sc}}\right)=1.44 \mathrm{~mA},\left(\mathrm{~V}_{\mathrm{oc}}\right)=0.524 \mathrm{~V}, \mathrm{FF}(\%)=65.30 \%$, $\eta(\%)=0.492 \%$ and MPPT $(\mathrm{mW})=0.492 \mathrm{~mW}$ for Kassod dyed, and $\left(\mathrm{I}_{\mathrm{sc}}\right)=0.217$ $\mathrm{mA},\left(\mathrm{V}_{\mathrm{oc}}\right)=0.362 \mathrm{~V}, \mathrm{FF}(\%)=35.99 \%, \eta(\%)=0.028 \%$ and MPPT $(\mathrm{mW})=0.028$ $\mathrm{mW}$ for senna dyed $\mathrm{TiO}_{2}$ and $\left(\mathrm{I}_{\mathrm{sc}}\right)=1.075 \mathrm{~mA},\left(\mathrm{~V}_{\text {oc }}\right)=0.474 \mathrm{~V}, \mathrm{FF}(\%)=$ $43.817 \%, \eta(\%)=0.223 \%$ and MPPT $(\mathrm{mW})=0.223 \mathrm{Mw}$ for Kassod + Senna dyed $\mathrm{TiO}_{2}$. These results satisfied the requirement for the production of DSSCs as confirmed in some other researchers' work. The SEM results show that there is a crack on the surface of the films. However, the cracks that were shown in the first SEM result in Figure 16(a) is far better than the cracks that appear on other SEM results in Figures 16(b)-(d). The reason for these discrepancies is that extending the deposition time of nanoparticles deteriorates the image of the formed film. The EDX graph revealed that the lattice structure of the film is spherical in nature. The results of this research work are recommended for the production of solar panels and photovoltaic materials.

\section{Conflicts of Interest}

The authors declare no conflicts of interest regarding the publication of this paper.

\section{References}

[1] O’Regan, B and Grätzel, M (1991) Manufacturing Dye Sensitized Solar Cells. Nature, 353, 737-740. https://doi.org/10.1038/353737a

[2] Nwokoye, A.O.C and Okoye, I.F (2020) Profilomatry Analysis of Flourine Doped Tin Oxide (FTO) Film Mesoporous $\left(\mathrm{M}-\mathrm{TIO}_{2}\right.$ ) Film Using Organic Dye from Senna Plant as a Photosensitizer. Der Chemica Sinica, 11, Article No. 2.

[3] Okoye, I.F (2020) Basic Applications in Energy and Power. Ahmadu Bello University Publisher and Press Limited, Zaria.

[4] Gerrit, B. (2019) Improving the Performance of Dye-Sensitized Solar Cells. Frontiers in Chemistry, 7, Article No. 77. https://doi.org/10.3389/fchem.2019.00077

[5] Hug, H., Bader, M., Mair, P. and Glatzel, T. (2013) Biophotovoltaics: Natural Pigments in Dye-Sensitized Solar Cells. Applied Energy, 115, 216-225. https://doi.org/10.1016/j.apenergy.2013.10.055

[6] Ugwu, L.O., Ozuomba, J.O., Ekwo, P.I. and Ekpunobi, A.J. (2015) The Optical Properties of Anthocyanin-Doped Nanocrystalline- $\mathrm{TiO}_{2}$ and the Photovoltaic Efficiency on DSSC. Der Chemica Sinica, 6, 42-48.

[7] Kabirad, F., Bhuiyan, M.M., Manira, M.S., Rahaman, M.S., Khana. M.A. and Ikegamic, T.I. (2019) Development of Dye-Sensitized Solar Cell Based on Combination of Natural Dyes Extracted from Malabar Spinach and Red Spinach. Results in Physics, 14, Article ID: 102474. https://doi.org/10.1016/j.rinp.2019.102474

[8] Ananthakumar, S., Balaji, D., Ram, K. and Sridharan, M.B. (2019) Role of Co-Sensitization in Dye-Sensitized and Quantum Dot-Sensitized Solar Cells. SN Applied Sciences, 1, Article No. 186. https://doi.org/10.1007/s42452-018-0054-3

[9] Ekanayake, A.W., Kumara, G.R.A., Rajapaksa, R.M.G. and Pallegedara, A. (2015) Increasing the Efficiency of a Dye-Sensitized Solid-State Solar Cell by Iodine Elimi- 
nation Process in Hole Conductor Material. Sensors \& Transducers, 12, 568-585.

[10] Nazeeruddin Md, K., Bessho, T., Cevey, L., Ito, S., Klein, C., De Angelis, F., Fantacci, S., Comte, P., Liska, P., Imai, H. and Graetzel, M. (2007) A High Molar Extinction Coefficient Charge Transfer Sensitizer and Its Application in Dye-Sensitized Solar Cell. Journal of Photochemistry and Photobiology, 185, 331-337. https://doi.org/10.1016/j.jphotochem.2006.06.028

[11] Ozuomba, J., Ekpunobi, A. and Ekwo, P. (2011) The Photovoltaic Performance of Dye-Sensitized Solar Cell Based on Chlorin Local Dye. Chalcogenide Letters, 8, 155-161.

[12] Al-Rawashdeh, N.A.F., Albiss, B.A. and Yousef, M.H.I. (2018) Graphene-Based Transparent Electrodes for Dye Sensitized Solar Cells. IOP Conference Series: Materials Science and Engineering, 305, Article No. 012019.

https://doi.org/10.1088/1757-899X/305/1/012019

[13] Andery, L., Noramaliyana, H.M., Kushan, T., Chandrakanthi, R.L., Linda, B.L., Sarath, B. and Piyasiri, E (2014) Higher Performance of DSSC with Dyes from Cladophora sp. As Mixed Cosensitizer through Synergistic Effect. Journal of Biophysics, 2015, Article ID: 510467. https://doi.org/10.1155/2015/510467

[14] Murakoshi, K., Kogure, R. and Yanagida, S. (1997) Solid State Dye-Sensitized $\mathrm{TiO}_{2}$ Solar Cell with Polypyrrole as Hole Transport Layer. Chemistry Letters, 26, 471 472. https://doi.org/10.1246/cl.1997.471

[15] Ito, S., Murakami, T.N. and Comte, P. (2007) Fabrication of Thin Film Dye Sensitized solar Cells with Solar to Electric Power Conversion Efficiency over 10\%. Thin Solid Films, 516, 4613-4619. https://doi.org/10.1016/j.tsf.2007.05.090

[16] Mehmood, U., Rahman, S., Harrabi, K., Hussein, I.A. and Reddy, B.V.S. (2014) Recent Advances in Dye Sensitized Solar Cells. Advances in Materials Science and Engineering, 2014, Article ID: 403585. https://doi.org/10.1155/2014/974782

[17] Hagfeldt, A. and Grätzel, M. (2000) Molecular Photovoltaics. Accounts of Chemical Research, 33, 269-277. https://doi.org/10.1021/ar980112j

[18] Dai, Q. and Rabani, J. (2002) Photosensitization of Nanocrystalline $\mathrm{TiO}_{2}$ Film by Anthocyanin Dyes. Journal of Photochemistry and Photobiology A: Chemistry, 148, 17-24. https://doi.org/10.1016/S1010-6030(02)00073-4

[19] Furukawa, S., Lino, H., Iwamoto, T., Kukita, K. and Yamauchi, S. (2009) Characteristics of Dye-Sensitized Solar Cells Using Natural Dye. Thin Solid Films, 518, 526 529. https://doi.org/10.1016/j.tsf.2009.07.045

[20] Lin, J.T., Chen, P.C., Yen, Y.S., Hsu, Y.C, Chou, H.H, and Yeh, M.C.P. (2009) Organic Dyes Containing Furan Moiety for High-Performance Dye-Sensitized Solar Cells. Organic Letters, 11, 97-100. https://doi.org/10.1021/ol8025236

[21] Macht, B., Turrión, M., Barkschat, A., Salvador, P., Ellmer, K. and Tributsch, H. (2002) Patterns of Efficiency and Degradation in Dye Sensitization Solar Cells Measured with Imaging Techniques. Solar Energy Materials and Solar Cells, 73, 163-173. https://doi.org/10.1016/S0927-0248(01)00121-0

[22] Hardin, B.E., Hoke, E.T., Armstrong, P.B., Yum, J.-H., Comte, P., Torres, T., et al. (2009) Increased Light Harvesting in Dye-Sensitized Solar Cells with Energy Relay Dyes. Nature Photonics, 3, 406-411. https://doi.org/10.1038/nphoton.2009.96

[23] Becquerel, A.E. (1839) Memoire sur les effets electriques produits sous l'influence des rayons solaires. Comptes Rendus de I Academie des Sciences, 9, 561-567

[24] Calogero, G. and Di-Marco, G. (2008) Red Sililian Orange and Purple Eggplant Fruits as Natural Sensitizers for Dye-Sensitized Solar Cells. Solar Energy Materials and Solar Cells, 92, 1341-1346. https://doi.org/10.1016/j.solmat.2008.05.007 
[25] Calogero, G., Di-Marco, G., Cazzanti, S., Caramoni, S., Argazzi, R., Carlo, A.D. and Bignozzi, C.T. (2010) Efficient Dye-Sensitized Solar Cells Using Red Turnip and Purple Wild Sicilian Prickly Pear Fruits. International Journal of Molecular Sciences, 11, 254-267. https://doi.org/10.3390/ijms11010254

[26] Matt-Law, D. (1996) Calculation of the Photocurrent-Potential Characteristics for Regenerative Sensitized Semi-Conductor Electrodes. Solar Energy Materials and Solar Cells, 44, 119-155. https://doi.org/10.1016/0927-0248(96)00036-0

[27] Nguu, J.N., Aduda, B.O., Nyongesa, F.W. and Musembi, R.J. (2014) Electrophoretic Deposition of $\mathrm{TiO}_{2} / \mathrm{Nb}_{2} \mathrm{O}_{5}$ Composite Electrode Thin Films for Photovoltaic Application. Journal of Energy and Power Engineering, 8, 757-764.

[28] Lee, Y. and Kang, M. (2010) The Optical Properties of Nanoporous Structured Titanium Dioxide and Thephotovoltaic Efficiency on DSSC. Materials Chemistry and Physics, 122, 284-289. https://doi.org/10.1016/j.matchemphys.2010.02.050

[29] Kimpa, I.M. (2016) Fabrication and Analysis of Dye Sensitized Solar Cells Using Natural Dyes Extracted from Pawpaw Leaf and Flame Tree Flower and the Synthetic Rutheniumn Dye. Master Dissertation, Usmanu Danfodiyo University, Sokoto. 